\title{
Mucoepidermoid Carcinoma: A Demographic and Histopathological Profile
}

\author{
Zainab Niazi ${ }^{1}$, Imran Khan ${ }^{2}$, Farah Farhan ${ }^{3}$, Maria Ilyas ${ }^{4}$, Misbah Ali ${ }^{5}$, Syeda Rabbab Hasan ${ }^{1}$ \\ ${ }^{1}$ Assistant Professor, Islamabad Medical and Dental College, Islamabad Pakistan \\ ${ }^{2}$ Associate Professor, Islamabad Medical and Dental College, Islamabad Pakistan \\ ${ }^{3}$ Assistant Professor, Foundation College of Dentistry, Rawalpindi Pakistan \\ ${ }^{4}$ Senior Lecturer, Baqai Dental College, Karachi Pakistan \\ ${ }^{5}$ Assistant Professor, Margalla Institute of Health Sciences, Rawalpindi Pakistan
}

\begin{abstract}
Background: Mucoepidermoid carcinoma (MEC) is the most common malignant tumor of salivary glands, with a variable prevalence (9.5\%-25.6\% in Pakistan) and clinicopathological presentation. The objective of this study was to find out the frequency and clinicopathological presentation of mucoepidermoid carcinoma at Armed Forces Institute of Pathology, Rawalpindi Pakistan.

Material and Methods: This descriptive cross-sectional study was carried out at Armed Forces Institute of Pathology, Rawalpindi between June 2016 to September 2017. All the malignant salivary gland tumors fulfilling the diagnostic criteria for MEC were included and the frequency of mucoepidermoid carcinoma was calculated. Age, gender, histopathological grading and anatomical site of tumor were also evaluated.

Results: A total of 30 patients of mucoepidermoid carcinomas, 23 (76.66\%) males and 7 (23.33\%) females, with a mean age of $44.9 \pm 19.2$ years and age range of 6 to 88 years were reported. Regarding anatomical site, majority of the patients $(73.3 \%)$ had tumor in the parotid gland, $13.3 \%$ in submandibular gland and $13.3 \%$ had tumor in palate, retromolar area and posterior one third of the tongue. According to histopathological grading, $26.6 \%$ MEC were high-grade, $26.6 \%$ intermediate-grade and $36.6 \%$ were low-grade tumors.

Conclusions: Mucoepidermoid carcinoma was more common in males, in the third decade with parotid gland as the most common site for this tumor. On histopathology, low grade MEC on Auclair et al. grading had the highest frequency in our study cohort.

Key words: Auclair grading system, Mucoepidermoid carcinoma, Salivary gland tumors.

Authors' Contribution:
${ }^{1}$ Conception; Literature research;
manuscript design and drafting; ${ }^{2,3}$ Critical
analysis and manuscript review; Data
analysis; Manuscript Editing.

$\begin{array}{ll}\text { Correspondence: } & \text { Article info: } \\ \text { Zainab Niazi } & \text { Received: November 12, } 2019 \\ \text { Email: dr.zainabniazi@gmail.com } & \text { Accepted: November 12, } 2020\end{array}$
\end{abstract}

Cite this article. Niazi Z, Khan I, Farhan F, Ilyas M, Ali M, Hasan SR. Mucoepidermoid Carcinoma: A Demographic and Histopathological Profile. J Islamabad Med Dental Coll. 2020; 9(4): 298-302. Doi: 10.35787/jimdc.v9i4.460

Funding Source: Nil Conflict of Interest: Nil

\section{Introduction}

Salivary gland tumors are about $5 \%$ of all tumors of the head and neck region. ${ }^{1}$ of these, mucoepidermoid carcinoma is the most common malignant tumor accounting for $56.9 \%$ of all 
malignant salivary gland tumors. ${ }^{2,3}$ The prevalence of mucoepidermoid carcinoma in Pakistan is 9.5\%$25.6 \%$ and an overall worldwide incidence of $12-40 \%$ has been reported. ${ }^{4}$

The most common site for MEC carcinoma is major salivary glands (mostly parotid gland), where $60 \%$ to $90 \%$ of such lesions are present. ${ }^{5}$ In minor salivary glands, it accounts for $22.9 \%-37.1 \%$. MEC is more common in females (75\%), with a female to male ratio of $3: 1{ }^{6}$ The prevalence of mucoepidermoid carcinoma is highest in third to fifth decade of life. MECs consist of three cell types in differing proportions: mucous cells, epidermoid cells with squamoid differentiation and undifferentiated small cells. MEC is typically classified into 3 histologic grades (low, intermediate and high) based on a compilation of characteristics including necrosis, mitoses, atypical nuclei and size of the cystic component. ${ }^{7}$ Low-grade (grade 1) mucoepidermoid carcinoma usually does not metastasize and is often cured by appropriate surgery. Patients with highgrade (grade 3) MEC are at significant risk for presenting with positive lymph nodes and developing disease-progression and possibly disease-related mortality. The biological potential of intermediate-grade (grade 2) MEC lies somewhere in the spectrum between grade 1 and 3 tumors. The most commonly involved sites are parotid gland, palate, retromolar trigone, buccal and submandibular glands. ${ }^{8}$

MEC presents as firm, painless, and fixed swellings. The tumors in sublingual gland have pain in spite of small size. MEC of minor salivary glands, especially in the palate are papillary. Symptoms of MEC include pain, bleeding, dysphagia, trismus, and facial nerve palsy. ${ }^{8}$ Auclair et al. divided MEC histologically into three grades depending on parameters like intracystic component, mitosis, anaplasia, neural invasion and necrosis. Hence low grade tumors have a score of 0-4, intermediate grade, 5-6 and high grade tumors $7-14$, respectively. ${ }^{9}$ Unlike squamous cell carcinoma, in which TNM staging is applied uniformly, there is no consensus over staging of MEC. There are also other grading systems like AFIP grading, modified Healy system and Brandwein grading system. AFIP grading system was initially discovered for MEC of minor salivary glands. ${ }^{10}$ Auclair et al. gading system is useful in determining the biological behavior of MEC. ${ }^{9,10}$

Here we present the clinicopathological characteristics of MEC in patients presenting at a tertiary care hospital in Rawalpindi, Pakistan.

\section{Material and Methods}

This descriptive cross-sectional study was carried out at Armed Forces Institute of Pathology, Rawalpindi between June 2016 to September 2017. A total of 30 patients of malignant salivary gland tumors were included. All the pathology slides were reviewed and only tumors with adequate histological features fulfilling the diagnostic criteria for MEC of salivary gland tumors were included in the study. Necrosed, scanty and autolyzed tissue samples and incomplete records were excluded from the study. The sample size was calculated by using the formula $n=z^{2} \times p(1-p) / d^{2}$, whereas estimated proportion was $2 \%$, margin of error $5 \%$, confidence level $95 \%$ and prevalence was $25 \% .{ }^{11}$ The proposal was reviewed and approved by the Ethical Review Committee of Armed Forces Institute of Pathology, Rawalpindi.

Mucoepidermoid carcinoma was diagnosed on the basis of characteristic histopathological patterns on hematoxylin and eosin-stained slides. The data regarding gender, age and anatomic location of tumors were collected from the patients' records. Patients' age was stratified into three categories; 630 years, $31-60$ years and $\geq 60$ years, respectively. MEC were assessed by Auclair et al. grading system (low, intermediate and high grade) ${ }^{9}$ based on a compilation of histological characteristics including necrosis, mitoses, atypical nuclei and size of the 
cystic component. The collected data was analyzed by using SPSS version 22.0.

Results

A total of 30 patients of mucoepidermoid carcinoma, 23 (76.66\%) males and 7 (23.33\%) females, with a mean age of $44.9 \pm 19.2$ years and age range of 6 to 88 years were reported. The mean age of male patients was $48.4 \pm 18.1$ years, while mean age of female patients was $30.7 \pm 14.37$ years. Majority of the patients were between 31 to 60 years $(56.7 \%)$ followed by 6 to 30 years $(26.7 \%)$, while patient above 60 years were less in number (16.6\%) (Table I).

With regards to gender, MEC was more common in males as compared to females (Table I). Regarding anatomical site, majority of the patients (73.3\%) had tumor in the parotid gland, $13.3 \%$ in submandibular gland and $13.3 \%$ had tumor in palate, retromolar area and posterior one third of the tongue (Table I).

According to histopathological grading, 26.6\% MEC were high-grade, $26.6 \%$ intermediate-grade and $36.6 \%$ were low-grade tumors (Table I).

\begin{tabular}{|l|c|c|}
\hline Table I: Demographic characteristics of MEC ( $\mathbf{n}=\mathbf{3 0})$ \\
\hline Gender & $\begin{array}{c}\text { Number of } \\
\text { cases }\end{array}$ & Percentage \\
\hline Male & 23 & 76.6 \\
\hline Female & 7 & 23.4 \\
\hline Age groups (years) & & \\
\hline 6 to 30 years & 8 & 26.7 \\
\hline 31 to 60 years & 17 & 56.7 \\
\hline Above 60 years & 5 & 16.6 \\
\hline Site of MEC & & \\
\hline Parotid & 22 & 73.2 \\
\hline Submandibular & 4 & 13.3 \\
\hline $\begin{array}{l}\text { Posterior } 1 / 3^{\text {rd }} \text { of } \\
\text { tongue }\end{array}$ & 1 & 3.3 \\
\hline Retromolar area & 1 & 3.3 \\
\hline Palate & 2 & 6.6 \\
\hline Grades of MEC & & 26.7 \\
\hline High & 8 & 26.7 \\
\hline intermediate & 14 & 46.6 \\
\hline Low & & \\
\hline
\end{tabular}

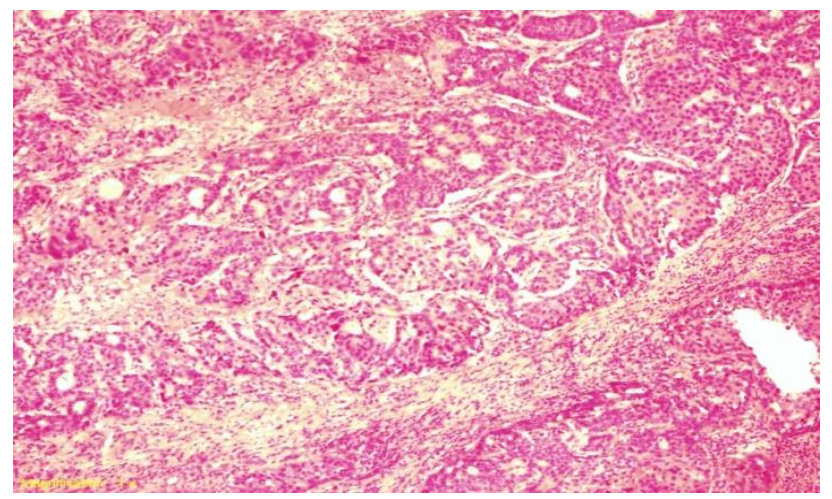

Figure 1: High grade MEC with predominant epidermoid cells (H\&E, 40x).

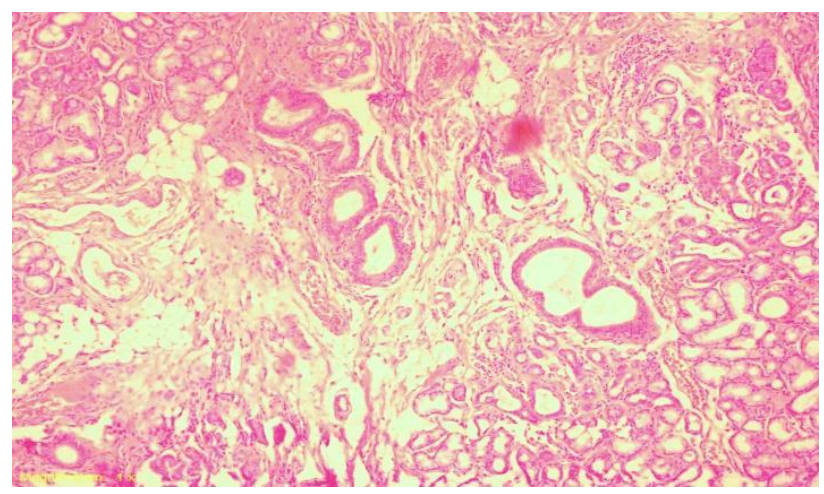

Figure 2: Low grade MEC showing cystic areas and mucus cells (H\&E, 40x)

\section{Discussion}

Mucoepidermoid carcinoma accounts for one third of all malignant tumors of major and minor salivary glands. It shows different biological behavior depending on histopathological grade of the tumor. ${ }^{11}$ However this aspect can only be proved in studies with larger sample size.

MEC was found mostly between 40 to 60 years of age in our patients with a mean age of 44 years as reported by many other studies. ${ }^{2-4,12}$ Qureshi et al., compared ages of patients with grades of MEC and observed that patients with increasing age are more susceptible to malignant tumors than patients in the younger age groups. ${ }^{4}$

There was a male predominance in the present study with a male to female ratio of 3:1. Unlike oral cancer, we could not identify any specific etiological factor for the male predominance of MEC. This is 
similar to studies conducted by Khiavi et al. ${ }^{12}$ and Rapidis et al. ${ }^{13}$ However, Rapidis et al. observed that history of radiotherapy might be regarded as a causative factor in males. ${ }^{13} \mathrm{~A}$ study conducted by Lujan et al. ${ }^{14}$ reported contrasting results with MEC more common in females as compared to males. Similarly, Bell et al. ${ }^{15}$ and Bai et al. ${ }^{3}$ reported male to female ratios of $1: 1.2$ and $1: 3$, respectively.

Parotid gland was the most common site of tumor followed by submandibular gland and palate. Our results correlate with studies conducted by Lujan et al. ${ }^{14}$ and Bai et al. ${ }^{3}$ In a study conducted by Al-Ani et al. ${ }^{16}$ in Baghdad, Iraq on 17 cases of MEC, submandibular salivary gland $(n=5)$ was the most common site for MEC, closely followed by parotid gland $(n=4)$.

Since MEC was first discovered, different grading systems have been used for classification of this entity. Some pathologists have used two-tiered grading systems, while we used three-tiered grading system according to Auclair et al. Low grade MEC was the most common histopathological variant of tumor in our study, followed by intermediate and high grade MEC, respectively. This is in agreement with Kokemueller and Okabe, ${ }^{17}$ who also reported that MEC of major salivary glands have less aggressive behavior as compared to MEC of minor salivary glands. Similarly, in our study $73 \%$ of cases of MEC were in the parotid gland. According to Khiavi et al., high grade MEC was the most common variant $(41 \%)$ followed by low grade $(31 \%)$ and intermediate grade (13\%), respectively. ${ }^{12}$ Another study conducted by Bai et al. also reported high grade MEC as the most common tumor. ${ }^{3}$

\section{Conclusion}

Mucoepidermoid carcinoma was more common in males, in the third decade with parotid gland as the most common site for this tumor. On histopathology low grade MEC on Auclair grading had the highest frequency in our study cohort.

\section{References}

1. Neville BW, Damn DD, Allen CM, Bouquot JE. Oral and

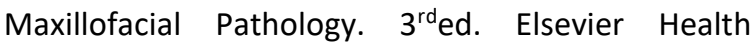
Sciences; 2015.

2. Gill MS, Muzaffar S, Soomroi IN, Hussainy AS, Pervez $\mathrm{S}$, Hasan SH. Morphological patterns of salivary glands tumors. J Pak Med Assoc. 2001; 51(10): 343-6.

3. Bai S, Clubwala R, Alder E, Sarta C, Schiff B, Smith RV, et al. Salivary Mucoepidermoid carcinoma: A multiinstitutional review of 76 patients. Head Neck Pathol. 2013; 7(2): 105-12. Doi: 10.1007/s12105-012-0405-0.

4. Qureshi SM, Janjua OS, Janjua SM. Mucoepidermoid carcinoma: A clinico-patholological review of 75 cases. Int J Oral Maxillofac Pathol. 2012; 3: 5-9.

5. Regezi JA, Sciubba JJ, Jordan RCK. Oral Pathology, Clinical Pathological Correlation. $5^{\text {th }}$ th edition. U.P: Saunders-Elsevier; 2009.

6. Ozawa H, Tomita T, Sakamoto K, Tagawa T, Fujii R, Kanazaki S. Mucoepidermoid carcinoma of the head and neck: clinical analysis of 43 patients. Japan J Clin Oncol. 2008:414-8

7. Deihimy P, Mahzoomi P, Torabinia N. Study of myoepithelial cell markers in pleomorphic adenoma and mucoepidermoid carcinoma of salivary glands. Dent Res J. 2006;3(2):1-8.

8. Chen MM, Roman SA, Sosa JA, Judson BL. Histologic grade as prognostic indicator for mucoepidermoid carcinoma: A population-level analysis of 2400 patients. Head Neck. 2014; 36(2): 158-63.

9. Auclair PL, Goode RK, Ellis GL. Mucoepidermoid carcinoma of intraoral salivary glands evaluation and application of grading criteria in 143 cases. Cancer. 1992; 69(8): 2021-30.

10. Goode RK, El Nagger AK. Mucoepidermoid carcinoma. In: Barnes L, Eveson JW, Reichart P, Sidransky D, editors. World Health Organization Classification of Tumors: Pathology and Genetics of Head and Neck Tumours. Lyon: IARC Press; 2005. p. 219-20.

11. Niazi Z, Hashmi SN, Muneer S. Immunohistochemical expression of Epidermal Growth Factor in different grades of Mucoepidermoid Carcinoma of salivary glands. JIMDC. 2018; 7(4): 231-34.

12. Khiavi MM, Vosouughhosseini S, Saravani S, Halimi M. Immunohistochemical correlation of epidermal growth factor receptor and c-erb with histopathological grading of mucoepidermoid carcinoma. J Can Res Therp. 2012; 8(4): 586-90.

13. Rapidis AD, Givalos N, Gakiopoulou H, Stavrianos SD. Mucoepidermoid carcinoma of the salivary glands. Review of the literature and clinicopathological analysis. Oral Oncol. 2007; 43(2): 130-6. 
14. Lujan B, Hakim S, Moyano S, Nadal A, Caballero M, Diaz A, Valera A. Activation of the EGFR/ERK pathway in high-grade mucoepidermoid carcinoma of the salivary glands. Br J Cancer. 2010; 103(4): 510-16.

15. Bell D, El-Naggar AK. Molecular heterogeneity in mucoepidermoid carcinoma: conceptual and practical implications. Head Neck Pathol. 2013; 7(1): 23-7.
16. Al-Ani SA, Abdullah BH. Evaluation of epidermoid growth factor receptor (EGFR), proliferation (Ki-67) and apoptosis (P53) in salivary mucoepidermoid carcinoma in relation to tumor grade. J Bagh Coll Dent. 2012; 24(2): 43-7.

17. Kokemueller H, Brueggemann N, Swennen G, Eckardt A. Mucoepidermoid carcinoma of the salivary glandsclinical review of 42 cases. Oral Oncol. 2005; 41: 3-10x 